\title{
Transient pharmacologic lowering of $A \beta$ production prior to deposition results in sustained reduction of amyloid plaque pathology
}

Pritam Das ${ }^{1 *}$, Christophe Verbeeck', Lisa Minter ${ }^{2}$, Paramita Chakrabarty ${ }^{3}$, Kevin Felsenstein $^{3}$, Thomas Kukar ${ }^{4}$, Ghulam Maharvi ${ }^{1}$, Abdul Fauq ${ }^{1}$, Barbara A Osborne ${ }^{2}$ and Todd E Golde ${ }^{3 *}$

\begin{abstract}
Background: Alzheimer's disease (AD) is the leading cause of dementia among the elderly. Disease modifying therapies targeting $A \beta$ that are in development have been proposed to be more effective if treatment was initiated prior to significant accumulation of $A \beta$ in the brain, but optimal timing of treatment initiation has not been clearly established in the clinic. We compared the efficacy of transient pharmacologic reduction of brain A $\beta$ with a Y-secretase inhibitor (GSI) for 1-3 months (M) treatment windows in APP Tg2576 mice and subsequent aging of the mice to either $15 \mathrm{M}$ or $18 \mathrm{M}$.

Results: These data show that reducing $A \beta$ production in a 2-3M windows both initiated and discontinued before detectable $A \beta$ deposition has the most significant impact on $A \beta$ loads up to $11 \mathrm{M}$ after treatment discontinuation. In contrast, initiation of treatment for $3 \mathrm{M}$ windows from 7-10M or 12-15M shows progressively decreasing efficacy.

Conclusions: These data have major implications for clinical testing of therapeutics aimed at lowering $A \beta$ production, indicating that; i) these therapies may have little efficacy unless tested as prophylactics or in the earliest preclinical stage of $A D$ where there is no or minimal $A \beta$ accumulation and ii) lowering $A \beta$ production transiently during a critical pre-deposition window potentially provides long-lasting efficacy after discontinuation of the treatment.
\end{abstract}

Keywords: A $\beta$, Alzheimer's disease, APP, Therapeutics, $\gamma$-secretase inhibition

\section{Background}

Alzheimer's disease (AD) is the leading cause of dementia among the elderly. Numerous studies in humans have demonstrated the sequential development of various pathological features that characterize $\mathrm{AD}$ and the relationship of these pathologies to diagnosis of dementia [1]. These studies support the amyloid cascade hypothesis which posits that accumulation of $A \beta$ aggregates triggers a series of downstream pathologies that results in clinical $\mathrm{AD}$ [2]. $\mathrm{AD}$ has recently been proposed to have three pre-clinical stages, characterized in sequence

\footnotetext{
* Correspondence: das.pritam@mayo.edu; tgolde@ufl.edu

'Department of Neuroscience, Mayo Clinic College of Medicine, 4500 San Pablo Rd S, Jacksonville, FL 32224, USA

${ }^{3}$ Center for Translational Research in Neurodegenerative Disease, Department of Neuroscience, McKnight Brain Institute, College of Medicine, University of Florida, 1600 SW Archer Road, Gainesville, FL 32608, USA

Full list of author information is available at the end of the article
}

by the development of $A \beta$ pathology (stage 1), the presence of plaque pathology, neurofibrillary pathology and initial evidence for neurodegeneration (stage 2), and finally by the presence of stage 2 , pathologies plus evidence for subtle cognitive decline (stage 3 ). This progression likely occurs over a 10-20 year timeline [3].

The amyloid cascade hypothesis predicts that attenuating or preventing $A \beta$ aggregation and accumulation will attenuate or prevent the subsequent development of $\mathrm{AD}$. Strong experimental support for the amyloid hypothesis has supported the rationale for many therapeutic approaches targeting $A \beta$. Major investments have been made to develop inhibitors or modulators of $A \beta$ production [4]. $\gamma$-secretase inhibitors (GSIs), $\beta$-secretase inhibitors (BSIs) and $\gamma$-secretase modulators (GSMs) have been or are currently being tested in human AD trials. Both the GSM tarenflurbil (R-flurbiporfren), and the GSI semagacestat, failed to show efficacy in phase III human 
trials $[4,5]$. Several other GSMs, GSIs, and BSIs are currently in early stage trials. Based on the clinical failures of tarenflurbil and semagacestat as well as other anti-A $\beta$ therapies not targeting $A \beta$ production but its aggregation or clearance, we and others have begun to question whether targeting of $A \beta$ in symptomatic $A D$ may be a futile endeavor [6].

Given the framework provided by the amyloid cascade hypothesis, disappointing results from completed trials of anti-A $\beta$ therapies in patients with $\mathrm{AD}$, and several but limited preclinical studies supporting the concept that when targeting $A \beta$ "earlier is better" [7-9], we explored the relationship between long-term efficacy with respect to reducing amyloid loads and timing and duration of $A \beta$ lowering. In designing these studies, we were struck by the parallels between $A \beta$ accumulation in the mouse brain and in vitro studies of $A \beta$ aggregation. In vitro, $A \beta$ aggregates in a nucleation dependent polymerization reaction, which exhibits three phases: a lag phase in which nucleation occurs but not fibril formation, an exponential growth phase in which fibril formation and growth occur rapidly, and a plateau phase where fibril growth and formation slows [10]. Except for being more extended in terms of time, studies in APP Tg2576 transgenic mice show that $A \beta$ aggregation and accumulation follows a similar course in the brain [11]. There is an initial lag phase where no $A \beta$ aggregation and accumulation occurs, followed by an exponential accumulation phase, and finally when amyloid loads become AD-like, the growth slows or plateaus (see Figure 1A). Given these parallels, we tested the efficacy of transient lowering of $\mathrm{A} \beta$ production in 1-3M treatment "windows" corresponding to these various phases of deposition using the GSI LY-411,575 (LY) in APP Tg2576 mice. These data show that GSI treatment during the pre-deposition window $(4-7 \mathrm{M})$ before the early exponential phase of deposition (7-10M) or late exponential phase (12-15M) has by far the most efficacy in terms of reduction of plaque loads at $15 \mathrm{M}$ of age.

\section{Results and discussion}

\section{In vitro and in vivo dosing studies with Ly-411,575}

Ly-411,575 is potent orally bioavailable $\gamma$-secretase inhibitor [12]. We synthesized large quantities for these studies and then performed both in vitro and in vivo studies to validate Ly-411,575 potency. The IC50 in cell culture for LY-411,575 was between 1-3 nm (see Additional file 1: Figure S1A). Six hours after a single IP dose, $A \beta 40$ levels are reduced by $\sim 75 \%$ in the brain of non-depositing $\operatorname{Tg} 2576$ mice (Additional file 1: Figure $\mathrm{S} 1 \mathrm{~B})$. Oral administration (10 $\mathrm{mg} / \mathrm{kg} /$ day $)$ administered as a single dose reduces brain A $\beta 40$ levels 24 hours after the final dose (7 days) by $\sim 65 \%$ (Additional file 1 : Figure $\mathrm{S} 1 \mathrm{C}$ ) and plasma $\mathrm{A} \beta 40$ by $~ 95 \%$ (Additional file 1:
Figure S1D). Plasma A $\beta$ levels are reduced more quickly than brain levels following oral dosing with maximal inhibition seen after 3 days (Additional file 1: Figure S1D). For long term in vivo mouse studies, we tested administration of Ly-411,575 using various dosing strategies and time points (Table 1). Oral administration (formulated in rodent chow) continually for 2 weeks with either - $1 \mathrm{mg} / \mathrm{kg} /$ day or $2.55 \mathrm{mg} / \mathrm{kg} /$ day reduced brain $\mathrm{A} \beta 40$ levels by $\sim 50 \%$ and plasma $\mathrm{A} \beta 40$ by $~ 80 \%$, without overt toxicities ( Table 1). However, continuous oral dosing (>2 weeks) using the higher dose of $5 \mathrm{mg} / \mathrm{kg} /$ day or $10 \mathrm{mg} / \mathrm{kg} /$ day resulted in overt toxicities in mice (Table 1). Therefore, in all long term studies presented in this manuscript, we have used the $2.5 \mathrm{mg} / \mathrm{kg} /$ day dose formulated in rodent chow.

\section{Transient $A \beta$ reduction dramatically reduces the subsequent accumulation of amyloid plaques}

For these experiments, we transiently dosed $\mathrm{Tg} 2576$ mice with LY from 4-7M, 7-10M or $12-15 \mathrm{M}$ and aged treated mice to $15 \mathrm{M}$ (see Figure 1B for experimental design). To confirm efficacy of LY in all groups, we measured plasma $A \beta$ levels immediately after the last day of treatment in sentinel mice and showed a similar reduction in plasma $A \beta$ levels in all cohorts (Table 2). Following sacrifice at $15 \mathrm{M}$, levels of $\mathrm{A} \beta$ in the brain were examined. The 4-7M LY treatment significantly reduced $\mathrm{A} \beta$ deposition; plaque burden in the frontal cortex and hippocampus was decreased by $\sim 68 \%$ (Figure $1 C$ ) and FA-solubilized brain $\mathrm{A} \beta$ levels were reduced by $\sim 60 \%$ (Figure 1D). The 7-10M LY treatment non-significantly decreased $\mathrm{A} \beta$ plaque burden by $\sim 19 \%$ compared to controls (Figure $1 C$ ), whereas FA-solubilized $A \beta$ levels were reduced by $\sim 34 \%$ (Figure 1D). The $12-15 \mathrm{M}$ GSI treatment group had no significant effect on either plaque burden or FA-solubilized $A \beta$ levels (Figure 1C, D). We further evaluated effect of the 4-7M LY treatment on cored amyloid plaques and cerebral amyloid angiopathy (CAA). Compared to untreated control mice, there were significant reductions both in cored plaques in the frontal cortex and hippocampus ( $47 \%$ reduction) and CAA in the leptomeninges ( $\sim 1 \%$ reduction, Figure $2 \mathrm{~A}$, B). To further determine whether the magnitude of the effect diminished with further aging, we performed an additional experiment, where we aged 4-7M LY treated mice to $18 \mathrm{M}$, and again we observed significantly reduced $A \beta$ plaque burden and FA-solubilized $A \beta$ levels (Figure $2 \mathrm{C}$ ), demonstrating that the suppression of deposition was maintained even up 11 months after treatment was halted.

Because $A \beta$ deposition in mice follows an exponential course, we sought to determine how the observed reductions in $A \beta$ accumulation correlate with $A \beta$ accumulation to untreated mice. We compared $A \beta$ levels in the 


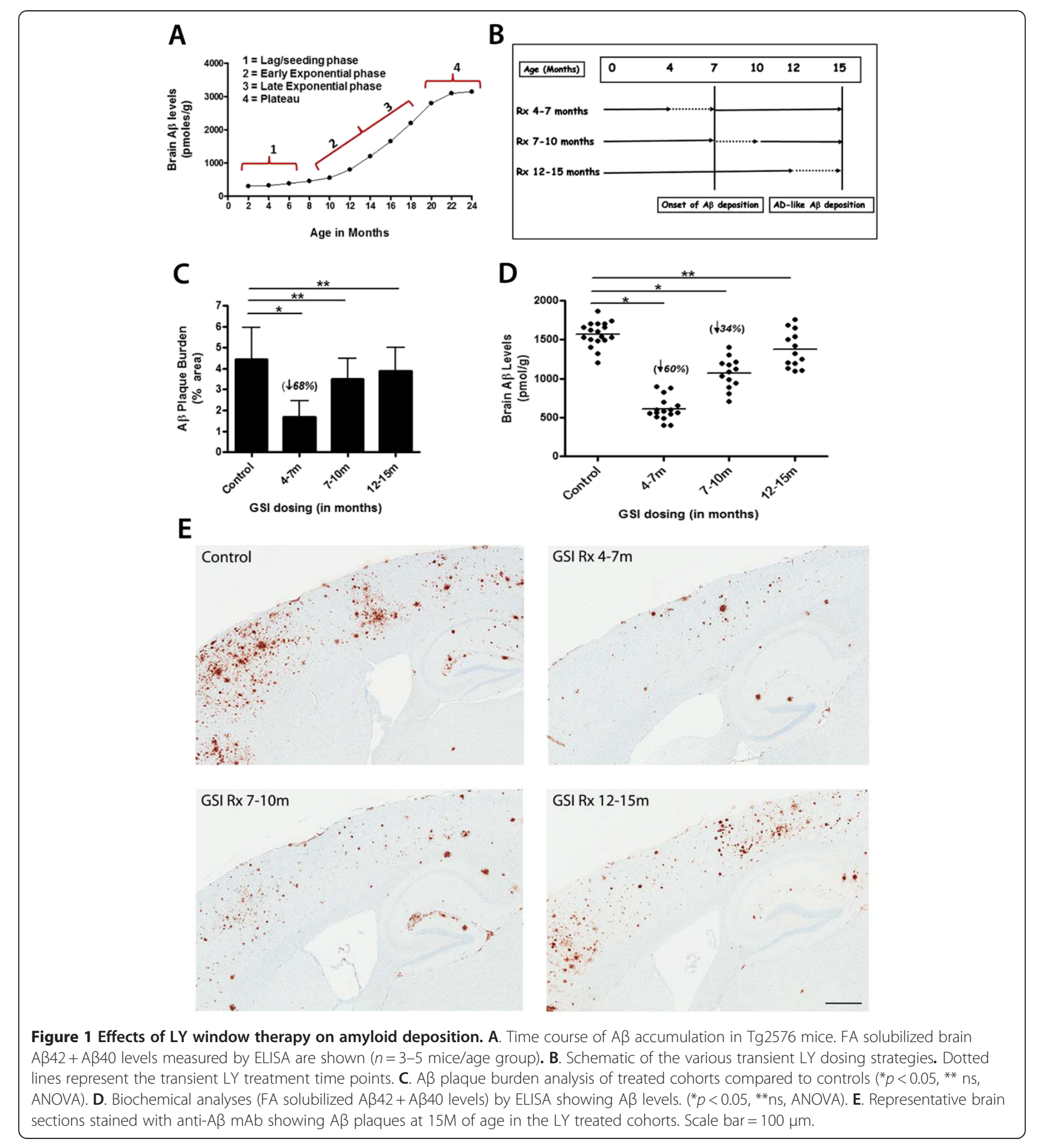

brains of untreated Tg2576 mice from various ages ranging from 10-18 months and plotted the natural logarithm transformed value of these against $A \beta$ levels from the 4-7M LY treated mice, aged to $15 \mathrm{M}$ and $18 \mathrm{M}$ (Figure 2D). To minimize variance, we assayed all of the samples in a single set of ELISA studies. This analysis showed that the $4-7 \mathrm{M}$ GSI treatment time frame "shifts" amyloid depositing by approximately 3 months, essentially delaying $A \beta$ accumulation by a time roughly equivalent to the treatment window.

We next attempted to determine whether this $4-7 \mathrm{M}$ narrow therapeutic "window" can be further refined. To do this, we transiently dosed Tg2576 mice with LY for 1, 2 or $3 \mathrm{M}$ intervals between the $4-7 \mathrm{M}$ age time frame and 
Table 1 Brain and plasma Aß40 levels following in vivo GSI treatment in Tg2576 mice

\begin{tabular}{|c|c|c|c|c|c|c|c|}
\hline Compound & $\begin{array}{l}\text { Strain } \\
\text { of Mice }\end{array}$ & Route & Dose & $\begin{array}{l}\text { Length of } \\
\text { Treatment }\end{array}$ & $\begin{array}{l}\text { \% A } \beta 40 \\
\text { Reduction } \\
\text { Brain }\end{array}$ & $\begin{array}{l}\text { \% A } \beta 40 \\
\text { Reduction } \\
\text { Plasma }\end{array}$ & $\begin{array}{l}\text { Overt } \\
\text { Toxicity }\end{array}$ \\
\hline \multirow[t]{3}{*}{ LY-411, 575} & $\operatorname{Tg} 2576$ & Intraperitoneal & $5 \mathrm{mg} / \mathrm{kg}$ & $6 \mathrm{hrs}$ & $75 \%$ & $92 \%$ & No \\
\hline & & & $10 \mathrm{mg} / \mathrm{kg}$ & $6 \mathrm{hrs}$ & $77 \%$ & $96 \%$ & No \\
\hline & & & $25 \mathrm{mg} / \mathrm{kg}$ & $6 \mathrm{hrs}$ & $78 \%$ & $92 \%$ & No \\
\hline \multirow[t]{3}{*}{ LY-411, 575} & $\operatorname{Tg} 2576$ & Oral (Suspension in Kool-Aid) & 10 mg/kg/day & 1 Day & $47 \%$ & $70 \%$ & No \\
\hline & & & & 3 Days & $65 \%$ & $86 \%$ & No \\
\hline & & & & 7 days & $75 \%$ & $95 \%$ & No \\
\hline \multirow[t]{4}{*}{ LY-411, 575} & $\operatorname{Tg} 2576$ & Oral (Formulated In Rodent Chow) & $1 \mathrm{mg} / \mathrm{kg} /$ day & 2 weeks & $36 \%$ & $67 \%$ & No \\
\hline & & & $2.5 \mathrm{mg} / \mathrm{kg} / \mathrm{day}$ & 2 weeks & $51 \%$ & $78 \%$ & No \\
\hline & & & $5 \mathrm{mg} / \mathrm{kg} /$ day & 2 weeks & $78 \%$ & $91 \%$ & Yes* $^{*}$ \\
\hline & & & 10 mg/kg/day & 2 weeks & $83 \%$ & $95 \%$ & Yes $^{*}$ \\
\hline
\end{tabular}

Tg2576 mice (3 months old) were dosed with GSI LY-411,575 using various routes, time points and indicated doses. After GSI treatment, groups of mice ( $n=3$ /group) were sacrificed and mouse brains were harvested and extracted in $2 \%$ SDS. Brain and plasma A 340 levels were then measured by ELISA. *Diarrhea and hair loss.

again aged the mice to $15 \mathrm{M}$. A $\beta$ levels were again significantly reduced in this second 4-7M LY cohort ( 59\% reduction) at $15 \mathrm{M}$ of age compared to controls (Figure 2E). Similarly, i) the 4-6M LY cohort showed a significant reduction in $\mathrm{A} \beta$ levels ( $\sim 51 \%$ reduction) and; ii) the 4-5M LY group showed a modest but nonsignificant reduction in $\mathrm{A} \beta$ levels $(\sim 24 \%$ reduction) (Figure 2E). However, in the remaining 5-6M, 6-7M or 5-7M LY cohorts tested, none showed any significant reductions in $\mathrm{A} \beta$ levels at $15 \mathrm{M}$ compared to controls (Figure 2E). Since we show that the 4-7M LY "shifts" amyloid deposition equivalently to the duration of treatment, we wondered whether we will see a similar shift in amyloid deposition in the shorter treatment intervals examined that showed efficacy, e.g., in the 4$5 \mathrm{M}$ and 4-6M cohorts. Again, we compared $\mathrm{A} \beta$ levels in the brains of untreated $\operatorname{Tg} 2576$ mice from various ages ranging from $10-15$ months against $A \beta$ levels from the 4-5M, 4-6M, and 4-7M LY treated cohorts aged to $15 \mathrm{M}$ (Figure 2F). This analysis seems to show that the 4-5M GSI treatment "shifts" amyloid depositing

Table 2 Plasma A $\beta 40$ levels following transient GSI treatment in Tg2576 mice

\begin{tabular}{|c|c|c|}
\hline Treatment Time & Treatment Groups & Plasma $A \beta 40(p M)$ \\
\hline \multirow[t]{2}{*}{ 4-7 Month } & Ly-411,575 & $341.3 \pm 20.1(81 \%)$ \\
\hline & Control & $1742.6 \pm 103.5$ \\
\hline \multirow[t]{2}{*}{ 7-10 Month } & $\underline{\text { Ly-411,575 }}$ & $327.5 \pm 18.5$ (79\%) \\
\hline & Control & $1520.7 \pm 100.8$ \\
\hline \multirow[t]{2}{*}{ 12-15 Month } & Ly-411,575 & $427.3 \pm 31.4(70 \%)$ \\
\hline & Control & $1388.4 \pm 223.2$ \\
\hline
\end{tabular}

Tg2576 mice were transiently dosed with GSI LY-411,575(2.5 mg/kg/day) at indicated time points. After GSI treatment was discontinued (on last day of treatment), plasma from groups of mice ( $n=3 /$ group) was collected and plasma $A \beta 40$ levels were measured by ELISA.

-Numbers in parenthesis represent percent reduction in $A \beta$ levels. by approximately 1 month, however, both the 4-6M and 4-7M treatment intervals essentially show a similar shift in $A \beta$ accumulation, namely by roughly 3 months (Figure 2F). These data would suggest, at least within the 4-7M time frame that we have studied, that the 4-6M age interval may play a critical role in the early seeding phases of amyloid deposition. Additional studies, using either earlier treatment times (e.g. starting at 3M of age) or longer treatment intervals may be necessary to fully appreciate the usefulness of this early "therapeutic window" to achieve the best possible outcome on subsequent amyloid deposition.

\section{Transient GSI does not permanently alter APP levels or processing}

To determine if the 4-7M LY treatment had longlasting effects on A $\beta$ production or APP levels and processing, we conducted a number of studies. We measured plasma $A \beta$ levels at termination of GSI treatment and then determined how long before steady state levels of $A \beta$ were normalized. Plasma $A \beta$ levels were significantly lower immediately after treatment, but returned to control levels between with 1-2 weeks after treatment was halted (Figure $3 \mathrm{~A}$ ). We also measured levels of full-length APP and APP C-terminal fragments (CTFs) in the brain at the end of the 4-7M treatment and at $15 \mathrm{M}$. Immediately following discontinuation of treatment, APP levels were unchanged but APP CTFs were increased (Figure 3B,D). However, at 15 months, there were no significant differences in full length APP or CTFs (Figure 3C,D). Finally, as GSI treatment has been shown to affect peripheral lymphocytes [13], we performed FACS analysis and quantified both $\mathrm{B}$ and $\mathrm{T}$ cell numbers in the spleen after the 4$7 \mathrm{M}$ LY transient treatment and at $15 \mathrm{M}$. B and $\mathrm{T}$ cell numbers were not affected (Figure 4A). However, when 


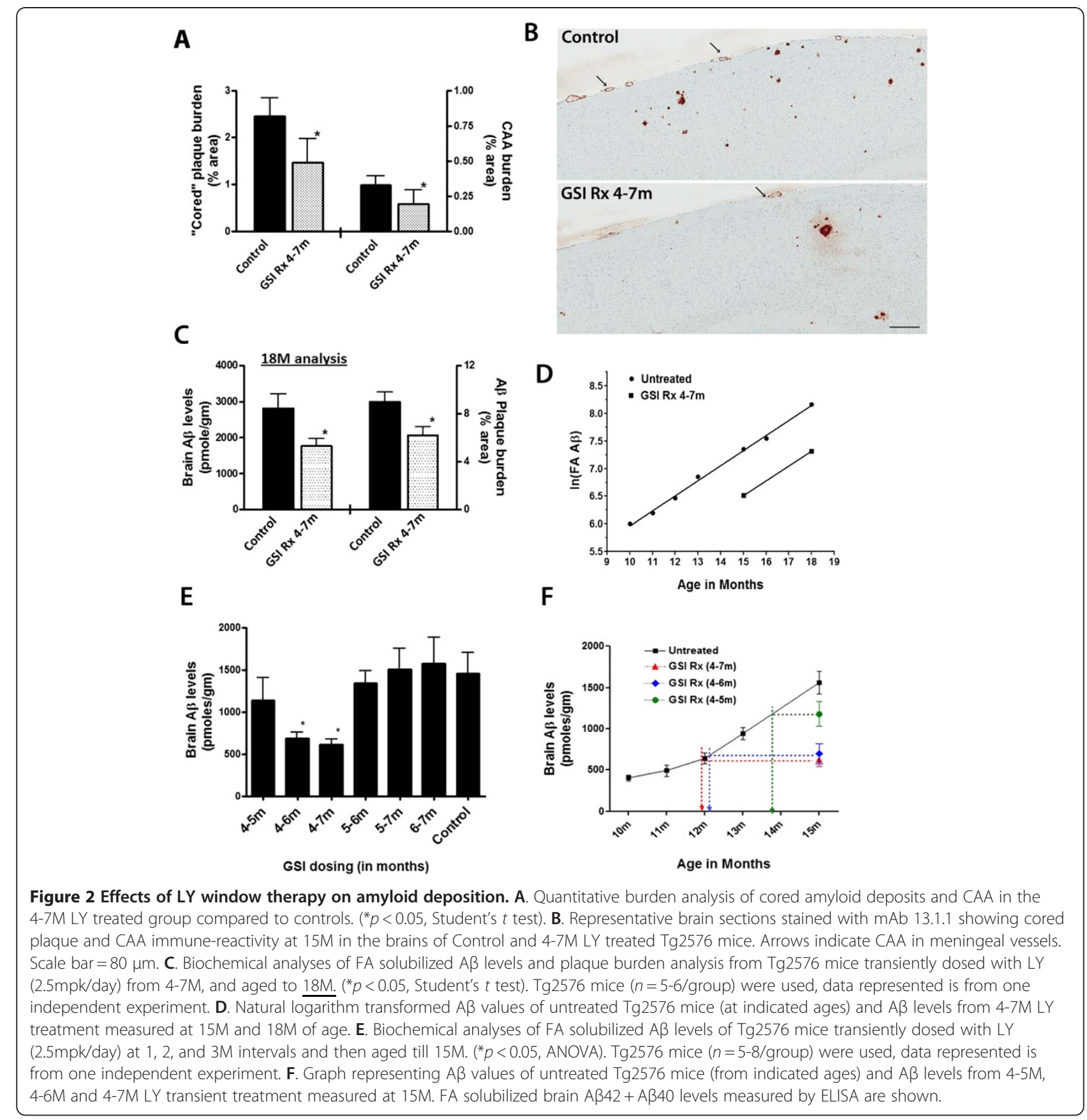

we analyzed Th1 and Th2 cytokine profiles, splenic CD4+ T cells from the 4-7M LY treated cohort showed a bias towards Th1 polarization with increased IFN- $\gamma$ secretion (a canonical Th1 cytokine) and concurrent decreases in IL-4 levels (a signature Th2 cytokine), which persisted even after the treatment was halted for 8 months (Figure 4B, C,). The significance of this longlasting effect on peripheral $\mathrm{CD} 4+\mathrm{T}$ cell immune responses is not clear, but certainly warrants further investigation.

\section{Conclusion}

Our current data show that transiently lowering $A \beta$ production in $\operatorname{Tg} 2576$ mice during the pre-deposition "seeding" phase has a major impact on subsequent $A \beta$ accumulation with the effect persisting for at least $11 \mathrm{M}$. Later treatment windows showed decreasing efficacy of treatment. These current data have major implications for trial design targeting $A \beta$ production in humans. Indeed, they would suggest that efficacy in terms of plaque reduction is likely to be maximal during seeding phase, 


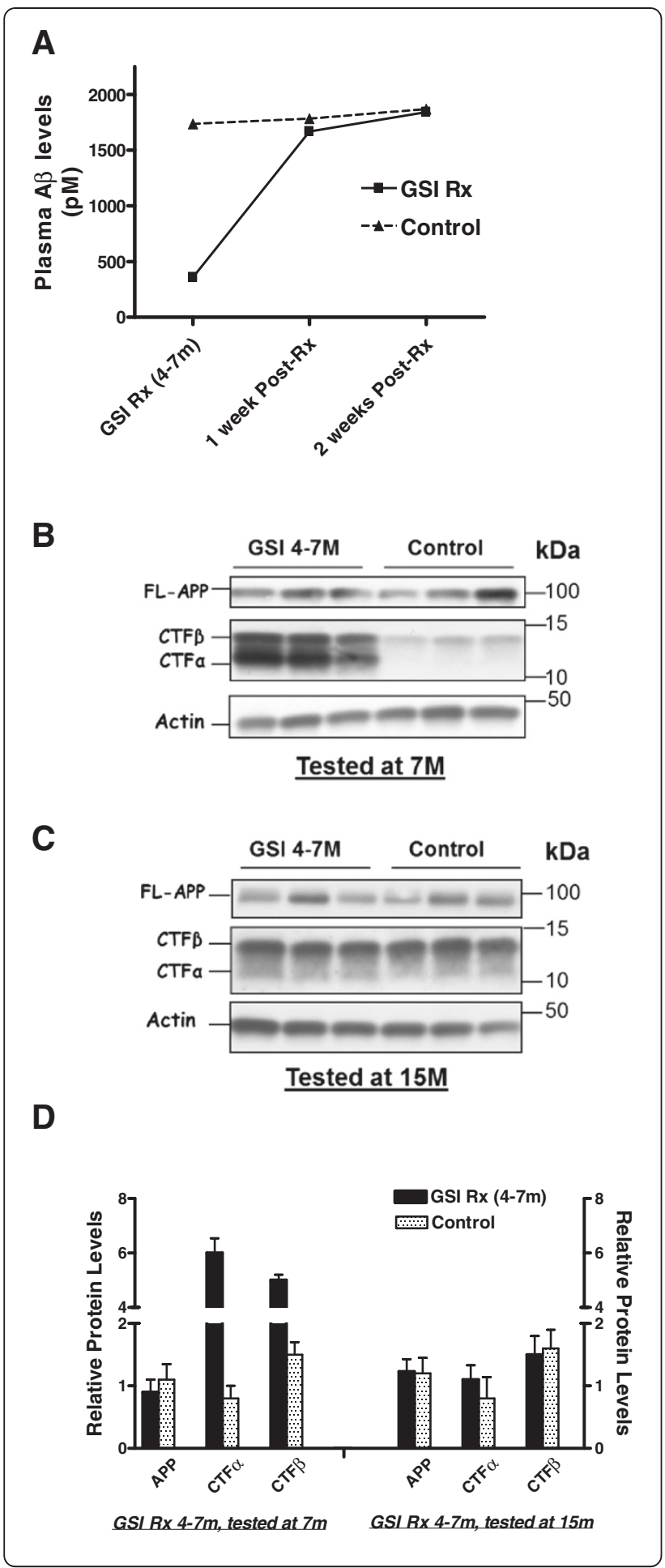

and rapidly decline if treatment is initiated during the exponential phase of deposition. A recent report [14] using passive immunotherapy provided more limited evidence that a similar effect may be observed with anti-A $\beta$ passive immunotherapy initiated during the early deposition phase persisting for 3 months after discontinuation
Figure 3 Long term LY treatment does not permanently affect APP levels or processing. A. Plasma A 440 levels by ELISA after the end of 4-7M LY treatment, (7M), 1 week after termination of treatment, and 2 weeks after termination of treatment. B. Representative anti-APP CT20 immunoblot shows APP levels and accumulation of CTFs after 4-7M LY treatment (tested at 7M). C. Representative anti-APP CT20 immunoblot showing full length APP levels and CTFs after transient 4-7M LY treatment (tested at 15M). D. Quantitative intensity analysis of anti-CT20 immuno-reactive full length APP and APP CTF protein levels normalized to actin.

of treatment. Given the plethora of anti-A $\beta$ therapies currently in development, it will be essential to determine for each modality whether efficacy is both maintained after discontinuation and similarly influenced by timing of the treatment.

The near equivalence of the delay in subsequent deposition to the length of the treatment window during a pre-deposition phase suggests that the GSI treatment from $4-7 \mathrm{M}$ alters or reverses seeding of $\mathrm{A} \beta$. Indeed, there are no plaques forming during this period of time. Future studies will be necessary to determine the exact mechanisms by which lowering $A \beta$ in this window alters subsequent deposition. As even in vitro detection of $\mathrm{A} \beta$ nucleation relies on indirect assays that have limited sensitivities, these studies will likely require a better understanding of nucleation and better assays to detect it. Developing such assays will be critical as direct translation of these studies would be facilitated by defining the equivalent window in humans. Regardless of mechanism, these preclinical window therapy studies have major implications regarding the potential of prophylactic therapy targeting $A \beta$ production in humans. Not only do these data suggest that prophylactic therapy in the appropriate window will be more efficacious then initiating therapy in individuals with any preexisting $A \beta$ pathology, but they suggest that such therapy, even if discontinued might delay subsequent onset $\mathrm{AD}$ by a time roughly equivalent to the time of treatment.

\section{Methods}

Tg2576 mice

APP Tg2576 mice were generated, maintained and genotyped as described previously [7]. All animal husbandry procedures performed were approved by the Mayo Clinic Institutional Animal Care and Use Committee in accordance with National Institutes of Health guidelines. All animals were housed three to five to a cage and maintained on ad libitum food and water with a $12 \mathrm{~h}$ light/dark cycle.

\section{LY-411, 575}

LY-411, 575 (LY) was synthesized at the Mayo Clinic Chemical Core as previously described [15]. LY at a 


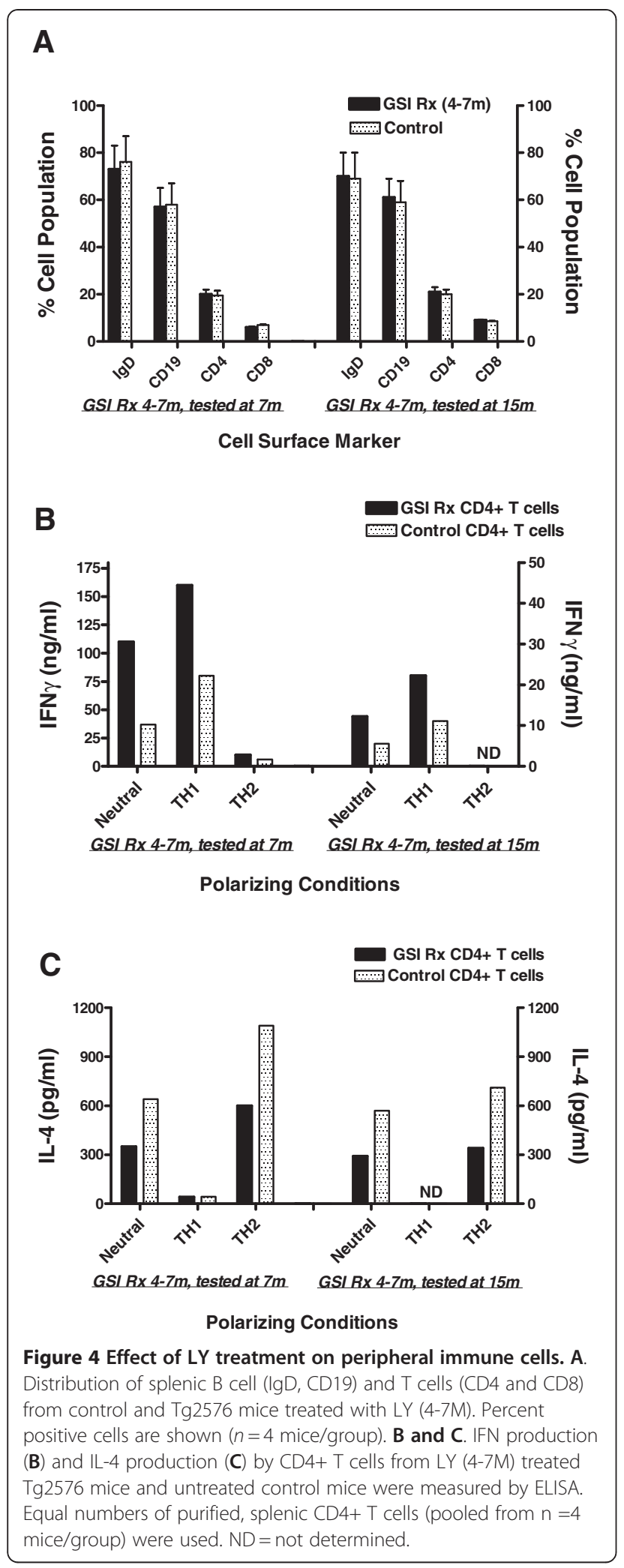

concentration of $16.75 \mathrm{mg}$ per $\mathrm{kg}$ of diet was homogenously incorporated into Harlan Teklad 7012 kibble chow by Research Diets, Inc, New Jersey). Based upon dietary consumption at this age, these diets were designed to deliver $2.5 \mathrm{mg}$ of LY on average per day. $\operatorname{Tg} 2575$ mice ( $n=7-15 /$ group/experiment) were transiently treated with LY chow at 1, 2 or 3 months interval (between 4-7 months of age), from 7-10 months of age and from 12-15 months of age. Untreated control mice from each age group were as aged and used for analysis. Groups of mice $(n=3)$ were sacrificed immediately after the end of each treatment time-point to access efficacy of LY inhibition. After treatment was halted, mice were then aged till 15 months or 18 months of age and then sacrificed for $A \beta$ analysis. Chow consumption, general health and body weight were monitored on a weekly basis in all treatment groups.

\section{Biochemical A $\beta$ ELISA assay}

Snap-frozen hemi-forebrains from $\operatorname{Tg} 2576$ mice were two-step sequentially extracted in 2\% SDS buffer followed by $70 \%$ formic acid (FA) as described previously [16]. A $\beta$ levels from brain lysates or plasma were the measured using sandwich ELISA techniques as described previously [16] with end specific mAbs 2.1.3 (human $\mathrm{A} \beta \mathrm{x}-42$ specific, Mayo) and $\mathrm{mAb}$ 13.1.1 (human $A \beta x-40$ specific, Mayo) for capture and HRPconjugated mAb Ab5 (human A $\beta 1-16$ specific, Mayo) for detection.

\section{Immunohistological analysis}

Sagittal sections of paraffin embedded sections were used for analysis. Immunohistochemical staining was done using pan- $\mathrm{A} \beta$ antibody ( $\mathrm{mAb}$ 33.1.1; Mayo), $\mathrm{mAb}$ 13.1.1 (human $A \beta x-40$ specific, binds cored plaques and CAA; Mayo) as previously described [17]. Immunohistochemically stained sections were captured using the Scanscope XT image scanner (Aperio, Vista, CA, USA) and analyzed using the ImageScope program. $A \beta$ plaque burden was then calculated using the Positive Pixel Count program (Aperio). At least 5 sections/brain $30 \mu \mathrm{m}$ apart, were used and averaged by a blinded observer to calculate plaque burden.

\section{Western blotting}

2\% SDS solubilized brain lysate samples were separated on Bis-Tris 12\% XT gels (Bio-Rad, Hercules, CA, USA) and probed with the antibody CT20 (anti-APP Cterminal 20 amino acid; 1:1000; P.D) and anti-actin (1:1000; Sigma, St. Louis, MO, USA). Band intensity was quantified using ImageJ software (National Institutes of Health, Bethesda, MD, USA). 


\section{Cell isolation, in vitro polarization and Immuno-phenotyping}

Single cell suspensions were prepared aseptically from spleens from control or GSI -treated mice. CD4+ T cells were positively selected using the BD-IMAG system and CD4 + DM particles (BD Biosciences, San Diego, CA), according to the manufacturer's directions. Twelve-well tissue culture plates were precoated with anti-hamster Ig (Sigma), then with antibodies specific for CD3€ and CD28. Equal numbers of cells $\left(3 \times 10^{6}\right)$ were added to each well. For TH1 polarizing conditions, anti-IL4 $(10 \mu \mathrm{g} / \mathrm{ml})$ plus IL-12 $(1 \mathrm{ng} / \mathrm{ml})$ was added to culture wells; for $\mathrm{TH} 2$ polarizing conditions, anti-IFN $\gamma$ $(10 \mu \mathrm{g} / \mathrm{ml})$ plus IL-4 $(1 \mathrm{ng} / \mathrm{ml})$ was added to culture wells. No additional reagents were added to cells cultured under neutral conditions. After 24 hours, all wells were pulsed with IL-2 $(10 \mathrm{ng} / \mathrm{ml})$. After 96 hours, supernatants were collected and frozen at $-80 \mathrm{C}$ until analyzed by ELISA for cytokine secretion. IFN $\gamma$ and IL- 4 cytokine secretion was measured using ELISA kits per manufactures instructions (BD Pharmingen). For cell surface staining, approximately $1 \times 10^{6}$ cells (each antibody) were stained with the following antibodies individually: IgD-FITC, biotinylated anti-CD19 plus strep-PE, CD4FITC, CD8-PE (BD Pharmingen). Data were analyzed using an LSRII flow cytometer (BD Biosciences) and FACSDiva software for acquisition and analysis.

\section{Statistics}

All statistics were done using Graphpad Prism (Version 5.0). Comparisons of multiple groups were done by oneway ANOVA followed by Tukey's post hoc testing. Comparisons between two groups were done by Student's $t$ test with Welch's correction for unequal variances where appropriate.

\section{Additional file}

Additional file 1: Figure S1A Wild type APP overexpressing $\mathrm{CHO}$ cells were treated with indicated concentrations of LY-411,575 overnight. Conditioned media were then assayed for secreted $A \beta 40$ by sandwich ELISA. Figure S1B. Acute LY-411,575 treatment reduces A $\beta 40$ levels in brains of mice. Tg2576 mice (3 month old) were injected with LY-411,575 $(5 \mathrm{mg} / \mathrm{kg}$ ) intraperitoneally. Mice were sacrificed $6 \mathrm{hrs}$ later and brain (2\% SDS solubilized) A 340 levels were measured ELISA.

( $n=3$ mice/group) Figure S1C, D. Tg2576 mice were dosed orally (suspended in Kool-Aid) with LY-411,575 (10 mg/ $\mathrm{kg})$ for indicated times and brain (2\% SDS solubilized) A 440 levels (C) and plasma $A \beta 40$ levels (D) were measured by ELISA ( $n=3$ mice/group).

\section{Competing interests}

The authors have no competing interests.

\section{Authors' contributions}

PD and TEG designed, analyzed and interpreted all aspects of the study and co-wrote the manuscript. CV performed all animal dosing studies, sacking and harvesting of tissues and ELISA analysis. PC performed western blotting techniques, tissue staining and quantification of plaque burdens. KF assisted with conceptualization of the study and edited the manuscript. TK performed in vitro cell culture analysis of LY-411, 575. GM and AF synthesized LY-411, 575 used in this study. LM and BAO performed immune cell isolation, in vitro polarization and immuno-phenotyping studies. All authors read and approved the final manuscript.

\section{Acknowledgements}

The authors thank Monica Castanedes-Casey, Virginia Phillips, and Linda Rousseau for assistance with histopathology. Supported by the National Institutes of Health/National Institute on Aging grant (P01AG25531 to BAO, TEG).

\section{Author details}

${ }^{1}$ Department of Neuroscience, Mayo Clinic College of Medicine, 4500 San Pablo Rd S, Jacksonville, FL 32224, USA. ${ }^{2}$ Department of Veterinary \& Animal Sciences, University of Massachusetts, 661 N. Pleasant St., Amherst, MA 01003, USA. ${ }^{3}$ Center for Translational Research in Neurodegenerative Disease, Department of Neuroscience, McKnight Brain Institute, College of Medicine, University of Florida, 1600 SW Archer Road, Gainesville, FL 32608, USA. ${ }^{4}$ Department of Pharmacology and Neurology, Emory University School of Medicine, 1510 Clifton Rd NE, 5123 Rollins Research Center, Atlanta, GA 30322, USA.

Received: 22 June 2012 Accepted: 6 August 2012

Published: 14 August 2012

\section{References}

1. Jack CR Jr, et al: Hypothetical model of dynamic biomarkers of the Alzheimer's pathological cascade. Lancet Neurol 2010, 9(1):119-128.

2. Hardy J, Selkoe DJ: The amyloid hypothesis of Alzheimer's disease: progress and problems on the road to therapeutics. Science 2002, 297(5580):353-356.

3. Dubois $B$, et al: Revising the definition of Alzheimer's disease: a new lexicon. Lancet Neurol 2010, 9(11):1118-1127.

4. Golde TE, Petrucelli L, Lewis J: Targeting Abeta and tau in Alzheimer's disease, an early interim report. Exp Neurol 2010, 223(2):252-266.

5. Imbimbo BP, Giardina GA: gamma-secretase inhibitors and modulators for the treatment of Alzheimer's disease: disappointments and hopes. Curr Top Med Chem 2011, 11(12):1555-1570.

6. Golde TE, Schneider LS, Koo EH: Anti-abeta therapeutics in Alzheimer's disease: the need for a paradigm shift. Neuron 2011, 69(2):203-213.

7. Das $P$, et al: Reduced effectiveness of Abeta1-42 immunization in APP transgenic mice with significant amyloid deposition. Neurobiol Aging 2001, 22(5):721-727.

8. Abramowski D, et al: Dynamics of Abeta turnover and deposition in different beta-amyloid precursor protein transgenic mouse models following gamma-secretase inhibition. J Pharmacol Exp Ther 2008, 327(2):411-424.

9. Levites $Y$, et al: Anti-Abeta42- and anti-Abeta40-specific mAbs attenuate amyloid deposition in an Alzheimer disease mouse model. J Clin Invest 2006, 116(1):193-201.

10. Jarrett JT, Lansbury PT Jr: Seeding "one-dimensional crystallization" of amyloid: a pathogenic mechanism in Alzheimer's disease and scrapie? Cell 1993, 73(6):1055-1058.

11. Kawarabayashi T, et al: Age-Dependent Changes in Brain, CSF, and Plasma Amyloid Protein in the Tg2576 Transgenic Mouse Model of Alzheimer's Disease. J Neurosci 2001, 21:372-381.

12. Dovey $H$, Varghese J, Anderson JP: Functional gamma-secretase inhibitors reduce beta-amyloid peptide levels in the brain. J Neurochem 2000, 76:1-10.

13. Wong GT, et al: Chronic treatment with the gamma-secretase inhibitor LY-411,575 inhibits beta-amyloid peptide production and alters lymphopoiesis and intestinal cell differentiation. J Biol Chem 2004, 279(13):12876-12882.

14. Karlnoski RA, et al: Suppression of amyloid deposition leads to long-term reductions in Alzheimer's pathologies in Tg2576 mice. J Neurosci 2009, 29(15):4964-4971.

15. Fauq $A H$, et al: $A$ multigram chemical synthesis of the gamma-secretase inhibitor LY411575 and its diastereoisomers. Bioorg Med Chem Lett 2007, 17(22):6392-6395. 
16. Chakrabarty $P$, et al: Massive gliosis induced by interleukin- 6 suppresses Abeta deposition in vivo: evidence against inflammation as a driving force for amyloid deposition. FASEB J 2010, 24(2):548-559.

17. Chakrabarty $P$, et al: IFN-gamma promotes complement expression and attenuates amyloid plaque deposition in amyloid beta precursor protein transgenic mice. J Immunol 2010, 184(9):5333-5343.

doi:10.1186/1750-1326-7-39

Cite this article as: Das et al:: Transient pharmacologic lowering of $A \beta$

production prior to deposition results in sustained reduction of amyloid plaque pathology. Molecular Neurodegeneration 2012 7:39.

\section{Submit your next manuscript to BioMed Central and take full advantage of:}

- Convenient online submission

- Thorough peer review

- No space constraints or color figure charges

- Immediate publication on acceptance

- Inclusion in PubMed, CAS, Scopus and Google Scholar

- Research which is freely available for redistribution 